\title{
Cytological Studies in the Genus Rosa III. Meiotic analysis of ten cultivars'
}

\author{
Pushpa Lata \\ Department of Plant Biology and Microbiology, Queen Mary College, \\ University of London, London E 1, U. K.
}

Received November 17, 1980

The present paper deals with the cytological studies, made on tetraploid $(2 n=28)$ rose cultivars. Six of these were related while the other four were selected for their desirable characters in the breeding experiments.

Studies were confined to male meiosis. Characters such as chromosome associations, chiasma frequency and other cytological irregularities were recorded with the possibility in mind that these might show some characteristic patterns of behaviour which could be traced back in the related cultivars.

\section{Materials and methods}

Rose cultivars Aunty Dora, Baronesse de Rothschild, Blue Moon, Godfrey Wynn, and Orangeade were obtained from Warley Roses Ltd., Essex; Dearest and Lilac Charm from Peter Beales Roses, Norwich; Crimson Glory and Fashion from George Longley Roses, Kent; and Spartan from the London University Botanical Supply Unit, Egham, Surrey.

Methods of chromosome preparation and observations were the same as described earlier (Lata 1981, 1982b).

\section{Results and discussion}

\section{Frequency of configurations}

The PMCs at diakinesis showed more than 30 different combinations of various configurations, involving univalents, bivalents and / or multivalents (Figs. 1-9). Cultivars Crimson Glory, Godfrey Wynn, Fashion and Spartan had 8-10 combinations; Aunty Dora had 20, and in the rest the number varied from 14-16. Most of these combinations were common in all cultivars but were present in different frequencies. Similar observations on tetraploid roses have also been made by earlier workers (Wylie 1954, Erlanson 1931, Shahare and Shastry 1963, Roberts 1977).

The cultivars were characterized by certain well marked meiotic associations of chromsomes which were recorded in about $50 \%$ or more PMCs of each cultivar (Table 1). Some of these related cultivars have been illustrated separately (Fig. 10) showing the inheritance of various associations in the hybrids. Of these related cultivars (Fig. 10) Geranium Red and Pinocchio were not studied.

\footnotetext{
${ }^{1}$ This work is a part of $\mathrm{Ph}$. D. thesis of the University of London.
} 


\section{Mean pairing}

The frequency of bivalents which would be 14 if all the 28 chromosomes formed bivalents (Fig. 2), was never more than 12.77. In five of the ten cultivars it was below 11.0, and fell as low as 10.06 in Blue Moon (Table 2). In other studies the frequency of bivalents was generally found to be high in tetraploid Rosa spp. (Roberts 1977). Shahare and Shastry (1963) recorded bivalent frequencies of 10.09-13.65 per

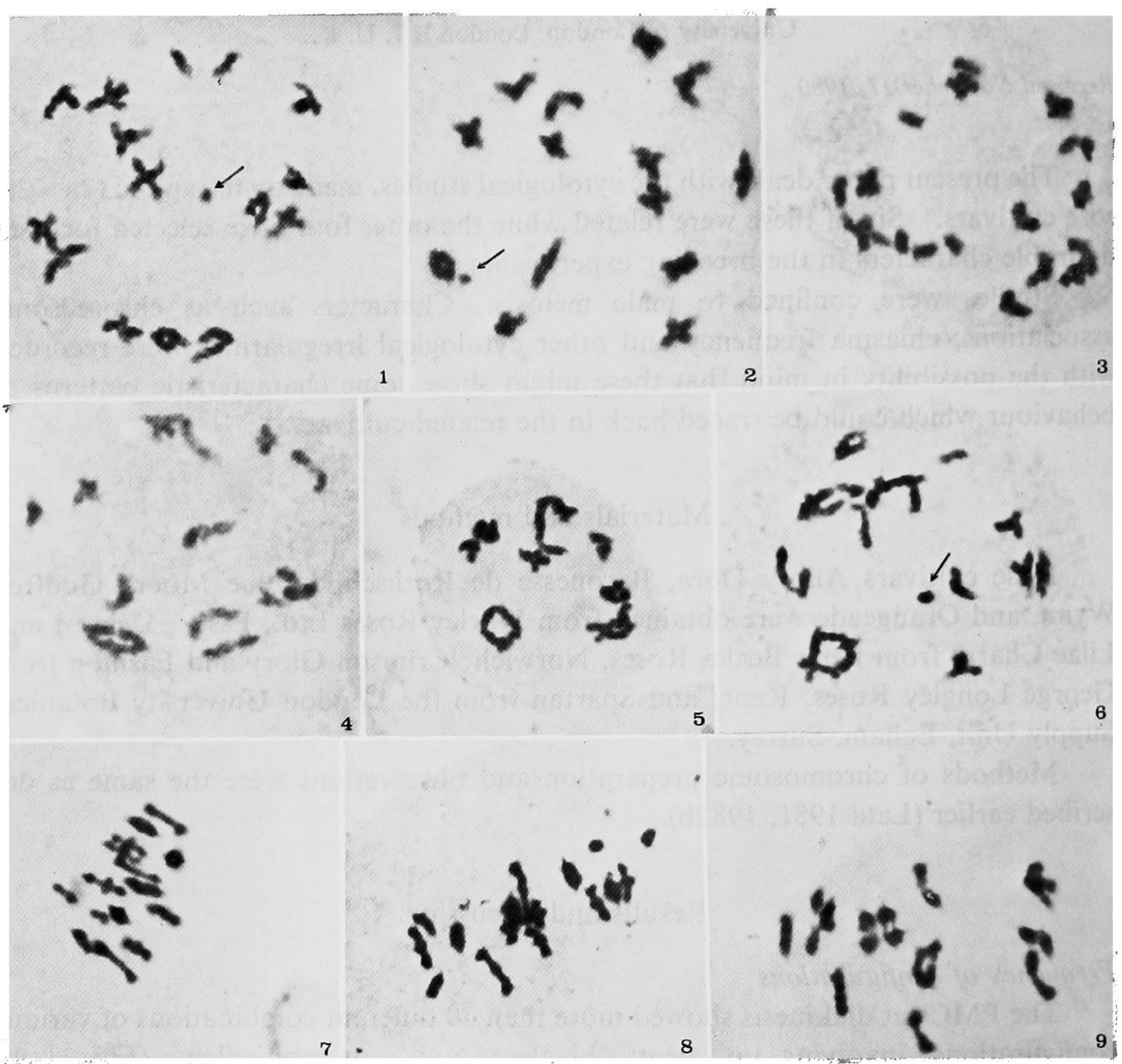

Figs. 1-9. Male meiosis in tetraploid $(2 n=28)$ rose cultivars. 1, chromosomes at diakinesis showing $2 \mathrm{I}+13 \mathrm{II}+\mathrm{B} . \quad 2,14 \mathrm{II}+\mathrm{B}$ in Aunty Dora. 3, $6 \mathrm{I}+11 \mathrm{II}$ in Dearest. 4, $12 \mathrm{II}+1 \mathrm{IV}$ in Fashion. 5, $8 \mathrm{II}+3 \mathrm{IV}$ in Lilac Charm. 6, $2 \mathrm{I}+9 \mathrm{II}+2 \mathrm{IV}+\mathrm{B}$ in Spartan. 7, first metaphases showing $2 \mathrm{I}+$ $13 \mathrm{II}$ in Baronesse de Rothschild. 8, $4 \mathrm{I}+12 \mathrm{II}$ in Blue Moon. 9, $2 \mathrm{I}+11 \mathrm{II}+1 \mathrm{IV}$ in Fashion. $\times 1600$. (arrow, B chromosome).

PMC in 55 tetraploid garden roses. The frequent formation of bivalents and univalents in tetraploids indicates their allotetraploidy nature.

The rose cultivars separate into two groups with regard to univalent frequency: Baronesse de Rothschild, Dearest and Spartan with frequencies of 2.1 and over and the rest with 1.4 or lower (Table 2). Two univalents were most common and were noticed at metaphase plates as precociously separating bivalents (Figs. 7-9). 


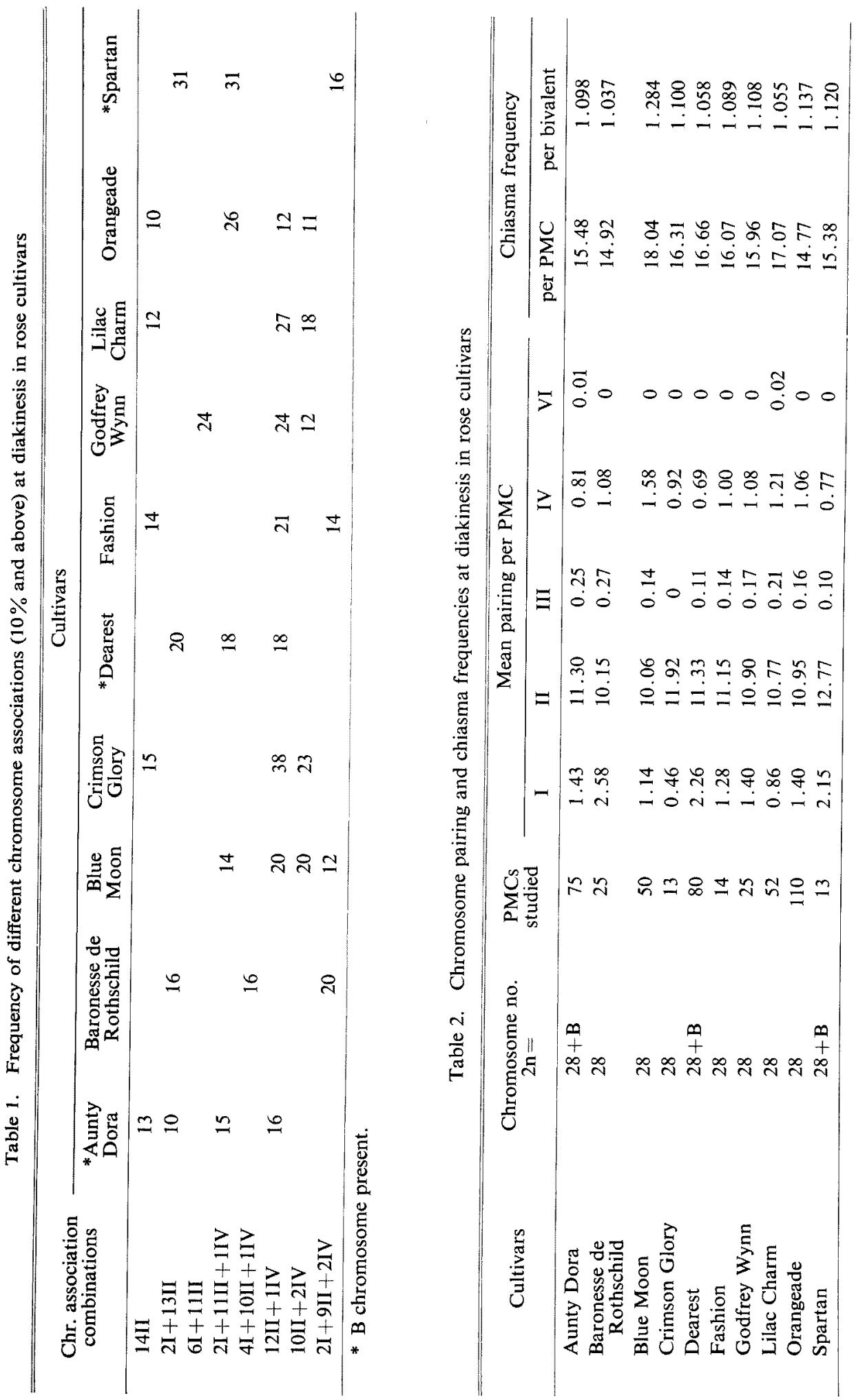


Trivalent frequency was particularly low, never above 0.27 per PMC and nil in Crimson Glory. Trivalents were recorded in certain tetraploid roses (Shahare and Shastry 1963, Roberts 1977) and their formation could result from inherited homology or translocations.

\section{PEDIGREE}

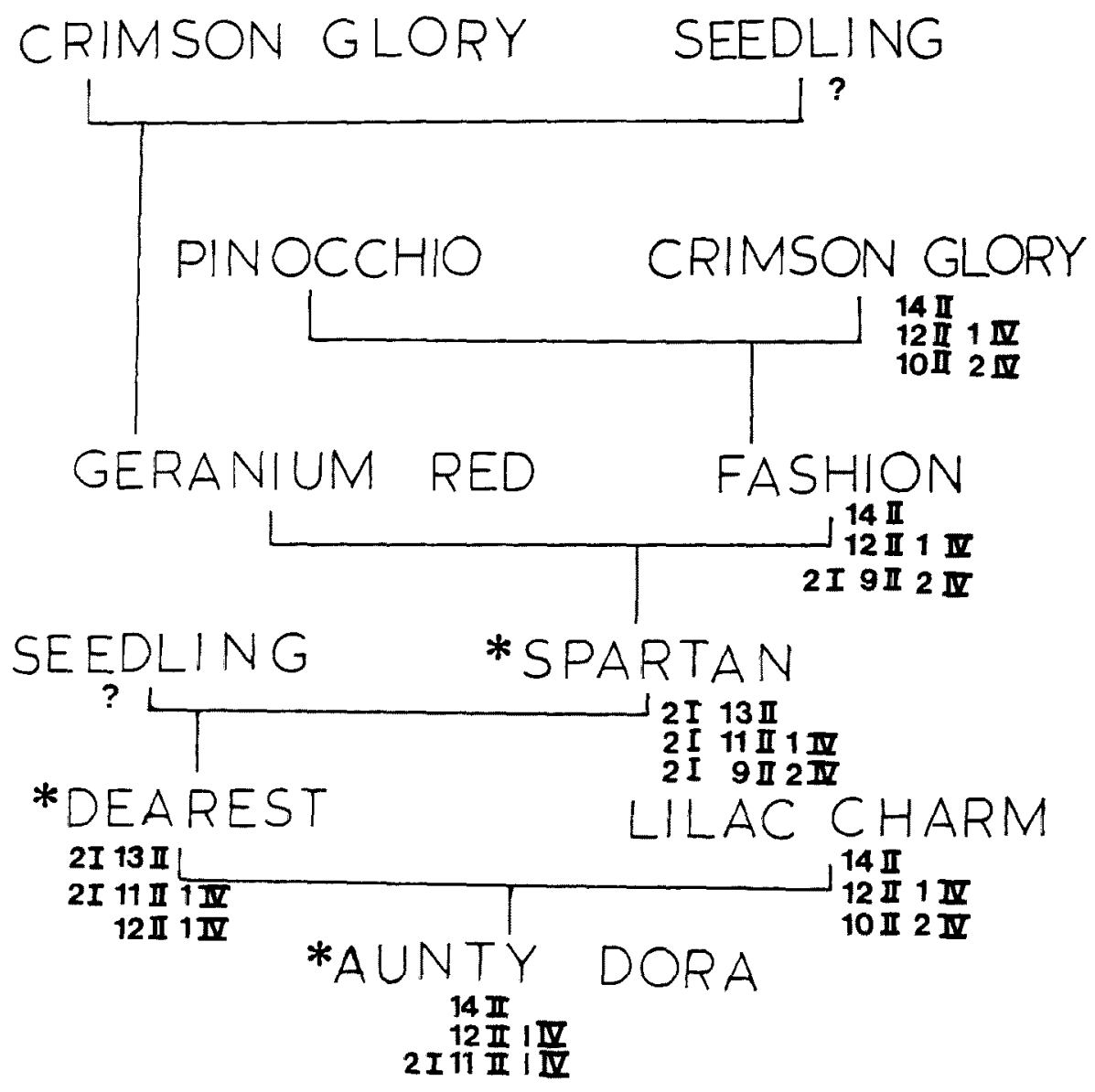

\section{*'B'CHROMOSOME PRESENT COMMON CHROMOSOME ASSOCIATIONS}

Fig. 10, Pedigree of Aunty Dora.

Whilst the commonest meiotic configuration contained 1 or 2 quadrivalents per PMC (Figs. 4, 6 and 9), more could be formed (Fig. 5). Quadrivalent formation was highest in Blue Moon (1.58) and lowest (0.69) in Dearest (Table 2). Quad- 
rivalent frequencies per cell were found as follows:-six and five in Blue Moon (in two cells and one cell respectively); three and four in Aunty Dora (in one cell each); whilest six cells of Orangeade, four of Blue Moon, three of Lilac Charm and one of Fashion each possessed three quadrivalents. The formation of so many quadrivalents per PMC points to the presence of homoeologous groups of four chromosomes or presence of translocations (John and Lewis 1965). In about $50 \%$ of tetraploid roses which formed quadrivalents (Shahare and Shastry 1963) their frequency varied from 0.07-1.0 per PMC. In another study (Lata 1975, Lata and Gupta 1975) 35 and $60 \%$ of PMCs of tetraploid roses contained quadrivalents. In the present study of ten cultivars, the quadrivalent frequency varied $49-86 \%$.

Only Aunty Dora and Lilac Charm ever formed hexavalents which again indicates the occurrence of translocations in these related cultivars.

\section{Chiasma frequency}

The chiasma frequencies varied from $14.77-18.04$ per PMC and from 1.0371.28 per bivalent (Table 2). The frequencies found in cultivars were low except in Blue Moon (18.04 per PMC and 1.28 per bivalent). These figures are comparable with those found for tetraploid roses, Rosa villosa and $R$. relicta (Erlanson 1931, 1933) and several garden roses (Shahare and Shastry 1963). A comparatively low figure (about 16 per PMC) has been reported for tetraploid $R$. spinosissima and a tetraploid hybrid (Roberts 1977). An identical figure (16.0 per PMC) was also recorded for tetraploid $R$. spp. in a previous study (Lata 1982b). Chiasma frequency is known to be under polygenic control (John and Lewis 1965) therefore variations in frequencies in different cultivars can result.

\section{Cytological irregularities}

Anaphase cells (Figs. 11-16) possessed considerable migrational irregularities (Table 3) which included various numbers of lagging chromosomes, dividing univalents and bridge formations (Figs. 12, 13 and 16). Unequal separation of chromosomes resulted mainly in distribution of 13:15 (Fig. 11) and occasionally one of 12:16. Some of the gametes with chromosome number variations were viable and could give rise to aneuploid plants (Lata 1982a). At anaphase I unequal separation was found in about $70 \%$ of PMCs of Aunty Dora, Baronesse de Rothschild, Blue Moon, Dearest and Orangeade. This must be an important factor in inducing pollen sterility (Table 3 ).

In some cases 'sticky bridges' were also observed (Fig. 13). Bridges were sometimes associated with fragments (Fig. 16). The anaphase bridges suggest the presence of paracentric inversions (Sybenga 1975, Brandham 1977). Lagging was also fairly common in all cultivars at second anaphases (Figs. 17 and 18) but bridge formation (Fig. 19) was seen only in 3 out of 10 cultivars. (Table 3). Lagging chromosomes were not included in the tetrads and were mostly lost (Fig. 20).

Cytological irregularities at second meiotic division resulted in formation of micronuclei: in $4 \%$ of cells of Crimson Glory, $51 \%$ of Blue Moon and $13-29 \% \mathrm{PMCs}$ of the remaining cultivars (Table 3 ).

A few PMCs of all cultivars gave rise to more than four pollen grains (Table 3 ). 


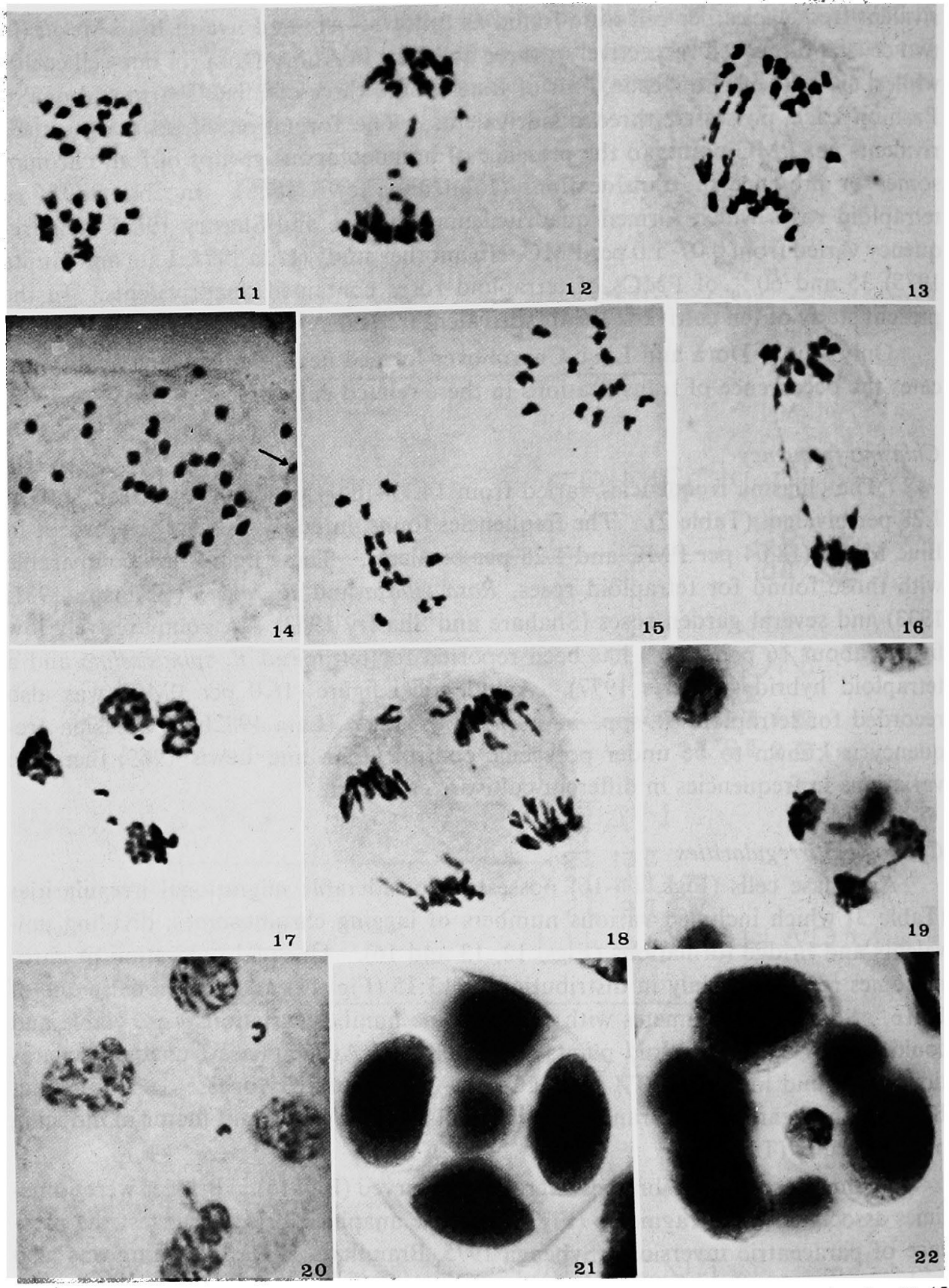

Figs. 11-22. Male meiosis in tetraploid $(2 n=28)$ rose cultivars. 11, first anaphases showing 13:15 segregation. 12, lagging chromosomes and dividing univalents in Baronesse de Rothschild. 13, 'Sticky bridge' formation in Blue Moon. 14, $28 \mathrm{I}+\mathrm{B}$ chromosome in Dearest. 15, 14: 14 segregation in Fashion. 16, bridge and lagging chromosome in Lilac Charm. 17, second telophase with 3 laggards in Aunty Dora. 18, late anaphase with 2 distally placed chromosomes in Blue Moon. 19, persistent bridge at late anaphase. 20, late second telophase with four macro-nuclei and two laggards in Orangeade. $\times 1600$. 21 and 22 , five and seven pollen grains per PMC in Aunty Dora. $\times 1200$. (arrow, B chromosome). 


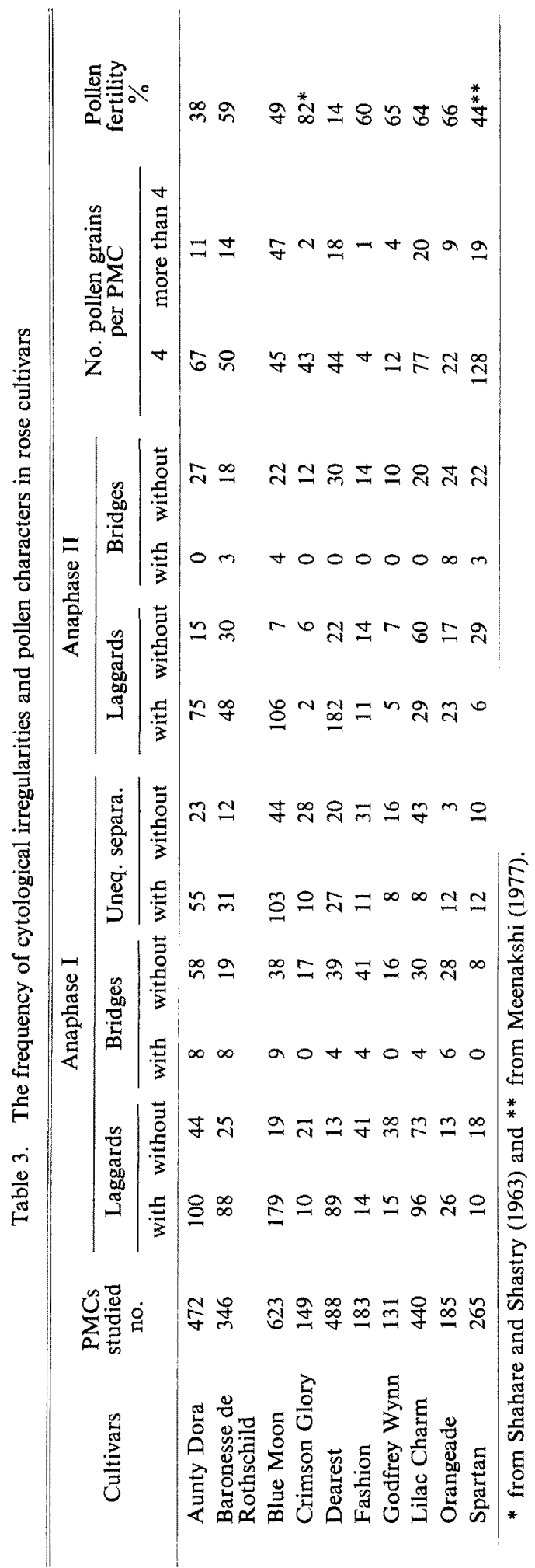


Five pollen grains per PMC (Fig. 21) were more frequent than any other higher numbers (Fig. 22), though sometimes as many as eight were formed.

Pollen fertility varied from $14-82 \%$ in various cultivars (Table 3). Between 50 to $66 \%$ fertile pollen grains were recorded in Baronesse de Rothschild, Blue Moon, Godfrey Wynn and Orangeade. Such low fertility has already been recorded in certain tetraploid garden roses (Shahare and Shastry 1963, Lata 1971, Meenakshi 1977). The figures for pollen fertility given by Shahare and Shastry (1963) are generally high. Pollen fertility was found to be higher (upto 97\%) in Rosa spp. (Roberts 1977) than in complex species hybrids (Roberts 1977, Lata 1982b). The high pollen fertility, in garden roses, was found to be associated with a high incidence of fruit set (Lata 1971, Meenakshi 1977).

\section{Inheritance of cytological characters}

The inheritance of certain common chromosome configurations was found in the related cultivars. Combinations of $14 \mathrm{II}$ or $12 \mathrm{II}+1 \mathrm{IV}$ were inherited from Crimson Glory to Fashion; and from Lilac Charm to Aunty Dora (Fig. 10). Similarly the combination of 2 I +9 II +2 IV was inherited from Fashion to Spartan whilest $2 \mathrm{I}+13 \mathrm{II}$ and $2 \mathrm{I}+11 \mathrm{II}+1 \mathrm{IV}$ occurred from Spartan to Dearest and $2 \mathrm{I}+$ $11 \mathrm{II}+1 \mathrm{IV}$ from Dearest to Aunty Dora (Fig. 10). The high frequency of univalents and bivalents per PMC in Aunty Dora, Dearest and Spartan, rather than a high frequency of quadrivalents as found in other cultivars (Table 1) may be accounted for by the presence of $\mathbf{B}$ chromosomes. The pattern of reduced pairing also indicated by $0.69-0.81$ quadrivalents per PMCs in cultivars with B chromosomes compared with $0.92-1.21$ in those cultivars lacking B's (Crimson Glory, Fashion and Lilac Charm).

Out of theses related cultivars (Fig. 10) Fashion was studied by Shahare and Shastry (1963) where the PMCs were found to have 1-3 quadrivalents, a trend also seen under present investigation.

Trivalents were formed with low frequency $(0.11)$ in Dearest as in its parent Spartan which had only 0.1 trivalents per PMC (Table 2). Dearest when used as a female parent in cross with Lilac Charm, gave rise to hybrid Aunty Dora with 0.25 trivalents per PMC. The increase in trivalent frequency in Aunty Dora would possibly have been inherited from the male parent, Lilac Charm where it was 0.21 .

The mean number of chiasmata per bivalent in related cultivars varied from 1.06-1.12 (Table 2). These figures were higher in Aunty Dora (1.098) than in its parents, i. e., Dearest and Lilac Charm (both with 1.06).

The various cytological irregularities were frequently observed in the related cultivars. The formation of more than four pollen grains per PMC varied in $4 \%$ of cases in Crimson Glory to $29 \%$ of cases in Dearest. A similar trend was seen with regard to pollen fertility figures (Table 3 ). Dearest had highly sterile $(86 \%)$ pollen while Lilac Charm was fairly fertile (64\%). As expected of a hybrid, Aunty Dora, was intermediate $(38 \%)$ with regard to pollen fertility. Fairly low fertility $(44 \%)$ was reported in Spartan (Meenakshi 1977). Spartan also possessed an additional B chromosome like Aunty Dora and Dearest. The association of a single B chromosome with male sterility was also recorded in Plantago coronopus (Paliwal and Hyde 1959). 
The foregoing results reveal that not only does each cultivar have characteristic meiotic pairing picture but also that the inheritance of features of pairing can be traced back to parental cultivars. Results obtained from present studies are in accordance with the findings made by several other workers on various tetraploid roses.

\section{Summary}

Male meiosis was studied in ten tetraploid $(2 n=28)$ garden roses. PMCs at diakinesis possessed univalents, bivalents and / or polyvalents in various frequencies. Certain combinations of chromosome associations were characteristic to each cultivar. The chiasma frequency varied from 14.77 to 18.04 per PMC and from 1.055 to 1.284 per bivalent. Various irregularities at first and second meiotic divisions resulted in 4 to $51 \%$ of PMCs with micronuclei formations which ultimately reduced the pollen fertility. Six out of ten cultivars were related and showed inheritance of various chromosome configurations. Three out of the six related cultivars carried an extra small B chromosome. This B was inherited for three generations and its presence was associated with higher univalent frequency per PMC and subsequently pollen sterility.

\section{References}

Brandham, P.E. 1977. The meiotic behaviour of inversions in polyploid Aloineae. Chromosoma 62: 69-84.

Erlanson, E. W. 1931. Chromosome organization in Rosa. Cytol. 2: 256-282.

- 1933. Chromosome pairing, structural hybridity and fragments in Rosa. Bot. Gaz. 94: 551-566. John, B. and Lewis, K. R. 1965. Protoplasmatologia. Springer-Verlag, Wien, N. Y. pp. 335.

Lata, P. 1971. Hybridization in modern roses. Curr. Sci. 40:4-6.

- 1975. Effects of ionizing radiations on roses II. Meiotic studies on rose cultivar Pink Parfait and its gamma ray induced mutants. Cytol. 40: 633-38.

- 1981. Occurrence and behaviour of B chromosomes in garden roses. The Nucleus 23: 194-198.

- 1982a. Inheritance of B chromosomes in garden roses. Genetica 58: 51-54.

- 1982b. Cytological studies in the genus Rosa II. Meiotic analysis of ten species. Cytol. 47: 631-637.

- and Gupta, M. N. 1975. Effects of ionizing radiation on roses: Meiotic studies on control and gamma ray induced mutants of rose cultivar Montezuma. Cytol. 40: 213-219.

Meenakshi, 1977. Sterility, its incidence and causes with special reference to roses. Indian Jour. Hort. 34: 437-445.

Paliwal, R. L. and Hyde, B. B. 1959. The association of a single B chromosome with male sterility in Plantago coronopus. Amer. J. Bot. 46: 460-466.

Roberts, A. V. 1977. Relationship between species in the genus Rosa, section Pimpinellifoliae. Bot. J. Linn. Soc. 74: 309-328.

Shahare, M. L. and Shastry, S. V. S. 1963. Meiosis in garden roses. Chromosoma 13: 702-724.

Sybenga, J. 1975. Meiotic Configurations, a Source of Information for Estimating Genetic Parameters. Berlin-Heidelberg- New York. Springer 1975.

Wylie, A. P. 1954. Chromosomes of garden roses. Amer. Rose Ann. 36-66. 